Criação / Poesia 


\title{
A variedade da poesia americana moderna
}

\author{
MARIA CLARA BONETTI PARO
}

$\mathrm{O}$

S POETAS aqui reunidos dão uma dimensão da variedade da poesia americana deste século, e as traduções permitem-nos explorar as sutilezas de cada poema com segurança e prazer.

Em ordem cronológica de nascimento, o primeiro é WALLACE STEVENS (18791955), o poeta moderno que Marjorie Perloff coloca como um dos quatro ou cinco melhores escritores americanos do século. Stevens começou a publicar sua obra com mais de 40 anos. Seu primeiro livro, Harmonium, é de 1923. Seguem-se Ideas of Order (1935), Owls Clover (1936), The Man With the Blue Guitar and Other Poems (1937), Parts of a World (1942), Notes Toward a Supreme Fiction (1942), Esthétique du Mal (1944), Transport to Summer (1947) e The Auroras of Autumn (1950). Em 1951 é publicado The Necessary Angel: Essays on Reality and the Imagination e, em 1954, Collected Poems deu-lhe o Prêmio Pulitzer e o National Book Award. Em 1957 , foram reunidos epigramas, ensaios, uma coleção de peças e alguns poemas publicados sob o título Opus Posthumous.

ELIZABETH BisHOP (1911-1979) é uma poeta personalíssima cuja obra afasta-se da experimentação estilística dos modernos e, também, dos preceitos da poesia Beat, da poesia de Black Mountain e a da Escola de Nova York. Viveu no Brasil de 1951 a 1979 e verteu para o inglês poemas de vários de nossos escritores. Sua poesia está reunida em The Complete Poems: 1927-1979. Seus textos em prosa estão publicados em The Collected Prose, e suas cartas podem ser lidas em português em Uma arte: as cartas de Elizabeth Bishop.

Frank O'HARA (1926-1966), assim como John Ashbery, é associado ao grupo que se convencionou chamar de Escola de Nova York. Com influência do dadaísmo e do surrealismo francês e inspirado pelos pintores expressionistas abstratos, como Jackson Pollock, Willem de Kooning, Jasper Johns, O'Hara tenta, em seus poemas, dialogar com outras artes. Seus livros de poesia são A City in Winter (1952), Meditations in an Emergency (1957) e Lunch Poems (1964). Em 1971, veio a público Collected Poems, onde está incluído o seu ensaio crítico sobre o papel do eu em sua obra, chamado Personism a Manifesto.Em 1978, publicou Collected Plays.

JOHN ASHBERY (1927- ), talvez o mais importante poeta americano da atualidade, é alinhado por Perloff na tradição anti-simbolista que vem de Rimbaud e passa por Gertrud Stein, Ezra Pound, William Carlos Williams e Samuel Beckett, através do dadaismo e da fase inicial do surrealismo. Seu livro Self-Portrait in a Convex Mirror recebeu três prêmios literários: o Pulitzer de 1976, o National Book Award e 
o National Book Critics Circle Prize. O poema que dá título ao livro foi analisado por Viviana Bosi Concagh, em tese defendida na USP: John Ashbery: um módulo para o vento. Em poesia: Some Trees (1956), The Tennis Court Oath (1962), Rivers and Mountains (1962), The Double Dream of Spring (1970), Three Poems(1972), SelfPortrait in a Convex Mirror (1975), Houseboat Days (1977), As We Know (1979), Shadow Train (1980), A Wave (1981), April Galleons (1987), Flow Chart (1991), Hotel Lautréamont (1992), And the Stars Were Shining (1994) e Can you Hear, Bird (1996).

MARK STRAND (1934- ) tem uma poesia introspectiva e meditativa que exprime o vazio e a solidão. Seu livro Reasons for Moring é considerado um exemplo de surrealismo americano. Esteve no Brasil como conferencista da Fulbright, em 196566. Suas publicações incluem livros de poesia como Sleeping with One Eye Open (1964), Reasons for Moving (1968), Darker (1970), The Story of our Lives (1973), The Late Hour (1978), Selected Poems (1980), The Continuous Life (1990). Entre suas traduções merece destaque Travelling in the Family (1986), com poemas de Carlos Drumond de Andrade.

Michael Palmer (1943- ) é um poeta inovador que participa de uma contratradição inaugurada pelo grupo Black Mountain College. Tem poemas incluídos em antologias dos Language Poets. Seus livros são Plan of the City of O (1971), Blake's Newton (1972), The Circular Gates (1974), Without Music (1977), Notes for Echo Lake (1981), First Figure (1984), Sun (1988) e At Passages (1995).

Maria Clara Bonetti Paro é professora do Departamento de Letras Modernas da Faculdade de Ciências e Letras da Universidade Estadual Paulista (Unesp-Araraquara). 